\title{
UMA ANÁLISE DA POLÍTICA EXTERNA DO GOVERNO LULA DA SILVA
}

Haroldo Ramanzini Júnior

\begin{abstract}
Resumo
O objetivo deste artigo consiste em analisar a política externa do governo Lula da Silva (2003-2010). A busca de projetar o país como ator relevante no sistema internacional e de fortalecer o multilateralismo foram elementos definidores da política externa brasileira. Ainda que esses não sejam objetivos totalmente novos na história da política externa brasileira, no governo Lula da Silva adquiriram renovada centralidade, em função de aspectos da política doméstica e de mudanças no sistema internacional. Nesse contexto o Brasil parece ter adquirido uma nova posição de razoável proeminência, ancorada na melhoria da realidade econômica e social do país e em ativismo internacional que busca o fortalecimento da multipolaridade.
\end{abstract}

Palavras-chave: Política Externa Brasileira; Multilateralismo; Governo Lula da Silva.

\begin{abstract}
The objective of this article is to analyse brazilian foreign policy during Lula's da Silva government (2003-2010). The search to project the country as a protagonist actor in the international system and to fortify the multilateralism had been defining elements of the brazilian foreign policy. Despite these are not totaly new objectives in the history of the brazilian foreign policy, in the Lula's da Silva government, they had acquired renewed centrality, due to aspects of domestic politics and changes in the international system. In this context Brazil seems to have achieved a new position of reasonable proeminence, anchored in the improvement of the economic and social reality of the country and in an international ativism that search the strengthening of the multipolarity.
\end{abstract}

Keywords: Brazilian Foreign Policy; Multilateralism; Lula da Silva Government.

\section{Introdução}

O objetivo deste artigo consiste em analisar a política externa brasileira durante o governo Lula da Silva. A principal característica da política externa brasileira durante o período 2003-2010 foi a busca de multilateralização do sistema internacional. Em diferentes situações o governo brasileiro se mostrou crítico do unilateralismo, sem perder a capacidade de diálogo com os países desenvolvidos. Houve políticas ativas de articulação internacional voltadas aos grandes países emergentes, buscando aumentar o poder de barganha e a capacidade de intervenção nos assuntos globais. O país aumentou e institucionalizou parcerias com países e regiões não-centrais, como 
África, Oriente Médio, Ásia e a América Latina. Houve ênfase na integração regional e na relação com os países vizinhos, no âmbito do MERCOSUL (Mercado Comum do Sul) e da UNASUL (União Sul Americana de Nações). Em função da centralidade do componente universalista a integração teve seu significado proporcionalmente reduzido. O Brasil teve uma política efetiva de cooperação regional, nem sempre idêntica à integração.

A participação ativa em arenas multilaterais é uma característica da política externa brasileira e se relaciona com o objetivo de parte das elites de projetar o país como um ator relevante na configuração do sistema internacional. Essa característica manifestou-se ao longo de todo o século $X X$. A noção de multilateralismo expressa a preferência por um padrão de interação coletiva nas suas diversas dimensões, seja como método de negociação, de ação ou de regulação, ao invés de priorizar ações unilaterais ou bilaterais. O Brasil, assim como outros países intermediários, tem interesse no multilateralismo institucionalizado com vistas a tentar aumentar a sua capacidade de negociação e prevenir o unilateralismo das potências. Pinheiro (2004) caracteriza a política externa brasileira com a noção de institucionalismo pragmático no sentido de que a preferência do país pela institucionalização varia conforme a arena da negociação e suas configurações de poder. Por exemplo, a resistência brasileira desde o começo dos anos 1990 de aprofundar a institucionalização do Mercosul (MARIANO, 2007), contrasta fortemente com a posição brasileira na OMC (Organização Mundial do Comércio), onde o país é um defensor da institucionalização e das regras. Isso pode ser concretamente verificado na diferença de assertividade do país na utilização de mecanismos institucionais de solução de controvérsias no âmbito do Mercosul e no âmbito da OMC.

No governo Lula da Silva, em função da natureza dos desafios colocados pelas transformações globais e da retomada das discussões sobre os parâmetros de legitimidade internacional, há uma tentativa do Brasil visando aumentar o seu peso nos órgãos internacionais tradicionais, como ONU (Organização das Nações Unidas), OMC e FMI 


\section{DOSSIÊ OS ANOS LULA}

(Fundo Monetário Internacional), buscando modificar as estruturas que consolidaram hierarquias no sistema internacional (MURPHY, 1994). Consolidam-se também uma série de arranjos multilaterais informais e seletivos, como o G-20 financeiro, que não podem ser vistos como alternativas ao padrão de multilateralismo tradicional. A questão da legitimidade é central para o Brasil, já que a influência do país no cenário externo não depende da sua capacidade coercitiva. Isto explica a importância atribuída aos órgãos tradicionais, que fundamentam a legitimidade, e aos órgãos informais, que consolidariam uma nova hierarquia que absorve países com crescente importância relativa.

Contribuir para o desenvolvimento ${ }^{1}$ econômico do país é também um objetivo definidor da política externa brasileira que, historicamente, é implementada tendo em conta os conceitos de autonomia e universalismo, enraizados na sociedade e no Estado. O significado concreto desses conceitos varia de acordo com a dinâmica do sistema internacional em determinado momento e de acordo com a perspectiva dos atores domésticos. Implicam a necessidade do país estar livre para agir no cenário externo, sem fortes condicionamentos. Isso se aplica nas relações do Brasil com os países em desenvolvimento e nos processos de integração regional. Tem forte significado para entender a relação com os países desenvolvidos, como Estados Unidos e União Européia. O conceito de autonomia se liga à busca de manutenção ou aumento das margens de manobra do país no sistema internacional. A noção de universalismo está associada às próprias características geográficas,

\footnotetext{
1 A noção de desenvolvimento, tal como presente na diplomacia brasileira, geralmente tem um significado amplo. Concretamente, o seu significado efetivo está associado às concepções correntes de uma época. A utilização diplomática da noção de desenvolvimento "permite conjugar tradicionalismo e, simultaneamente, manter as opções abertas às necessidades de ajustes governamentais de cada época" (MARIANO, 2007, p. 42). Portanto, a questão do desenvolvimento, no caso da política externa brasileira, é o elemento essencial que se relaciona à ação do governo, diferentemente da autonomia, que se liga com a ação do Estado. O seu significado concreto depende das mudanças no contexto internacional, mas, sobretudo, do contexto doméstico, do jogo de forças políticas, econômicas e sociais existentes no interior do Estado brasileiro e que se manifestam através de determinados períodos da história política nacional. Em relação à questão da relação entre desenvolvimento e política externa, no governo Lula da Silva, Soares de Lima (2010, p. 9) entende que "depois de um momento em que a política externa foi concebida como função assessora e auxiliar da estabilidade macroeconômica no sentido de reforço à restauração da credibilidade internacional, no primeiro Plano Plurianual do governo Lula restabeleceu a vinculação clássica entre política externa e estratégia de desenvolvimento".
} 
étnicas e culturais do país (LAFER, 2004) e consiste em diversificar os canais de interação e diálogo com o mundo.

Fundamentos políticos e diplomáticos significativos do governo Lula da Silva foram: a criação do grupo IBAS (India, Brasil e África do Sul) em junho de 2003 e do G-20 comercial $^{2}$, na reunião de Cancun da OMC; a contribuição para o adiamento sine-die das negociações da ALCA (Área de Livre-Comércio das Américas) em 2005; participação em Missões de Paz da ONU, especialmente no caso do Haiti; a contribuição para conferir uma instrumentalidade prática ao conceito de BRICs; esforços para fortalecer a democracia e as relações pacíficas entre os países latino - americanos, inclusão do tema da pobreza na agenda internacional, busca de diversificação das relações comerciais e políticas, com destaque para o papel da China, Índia, África do Sul e Rússia. A viabilização dessas articulações e posições tem relação com as oportunidades geradas pela difusão de poder no âmbito internacional, bem como com o papel singular do Itamaraty na definição da estratégia da política internacional do país.

A atuação internacional mediante coalizões Sul-Sul tem sintonia com o conjunto de políticas domésticas implementadas internamente pelo governo Lula da Silva e com a visão de mundo de parte significativa de suas elites e grupos de sustentação. O Itamaraty, com o apoio ostensivo da Presidência e articulando-se estrategicamente com burocracias médias, aproveitando a situação de fragilidade institucional da CAMEX (Câmara de Comércio Exterior), a instabilidade de outros ministérios e, apoiando-se em uma coalizão política e social que, não desejava que o Brasil se envolvesse em negociações profundas com países desenvolvidos, teve centralidade na formulação das principais posições internacionais no governo Lula da Silva. Isso seria mais uma demonstração da capacidade de adaptação do corpo diplomático às pressões domésticas e mudanças de governo, já identificadas na literatura (MARIANO, 2007; FARIA, 2008). Importante destacar que o

2 G-20 comercial/coalizões de países em desenvolvimento que atua em conjunta nas negociações agrícolas na OMC. São membros do Grupo: África do Sul, Argentina, Bolívia, Brasil, Chile, China, Cuba, Egito, Filipinas, Guatemala, India, Indonésia, México, Nigéria, Paquistão, Paraguai, Tailândia, Tanzânia, Uruguai, Venezuela e Zimbábue. 
fato de o governo Lula da Silva ter delegado ao Itamaraty ${ }^{3}$ a formulação da política externa e comercial externa brasileira, em relativo detrimento das burocracias econômicas, foi um atributo institucional importante que contribuiu para que a dimensão político-estratégica tivesse forte peso na agenda externa brasileira (EPSTEYN, 2009; FARIAS e RAMANZINI JÚNIOR, 2010). O que não quer dizer que os aspectos de ordem econômica tenham sido desconsiderados.

O artigo está dividido da seguinte forma. Na seção seguinte discutiremos elementos de mudança no sistema internacional que, em boa medida, contribuíram e viabilizaram algumas opções de política externa do governo Lula da Silva, fundamentadas na autonomia e no universalismo. Discutiremos também determinados aspectos da política de busca do fortalecimento do multilateralismo. Na terceira seção abordaremos a política regional do Brasil no governo Lula da Silva, no contexto das novas lideranças políticas latino-americanas. Nas considerações finais, apresentaremos os principais pontos discutidos.

\section{A política externa brasileira num mundo em transformação}

Com o fim da Guerra Fria muitos acreditaram que os Estados Unidos seriam a única potência mundial. Menos de vinte anos anos depois do fim da União Soviética, observamos que países emergentes como Brasil, China e Índia passam a ter maior influência em aspectos importantes da política internacional, num contexto em que surgem dúvidas quanto à centralidade absoluta dos Estados Unidos. As dificuldades internas norte-americanas, financeiras, relativas a valores, com enfraquecimento do seu soft power, os desafios para resolver crises internacionais, abrem o campo para mudanças de equilíbrios, tema de primordial interesse para o Brasil. Há movimentos buscando o fortalecimento do multilateralismo, para que outros atores participem efetivamente da gestão do sistema internacional, e não apenas os

\footnotetext{
3 Durante os oito anos do governo Lula da Silva, o embaixador Celso Amorim foi o Ministro das Relações Exteriores. De 2003 a 2009 o embaixador Samuel Pinheiro Guimarães foi o Secretário Geral do Itamaraty, sendo sucedido a partir de 27/10/2009 pelo embaixador Antonio de Aguiar Patriota.
} 
principais países desenvolvidos, como ocorreu na maior parte do período pós-1945.

Uma característica importante do cenário internacional durante o governo Lula da Silva é a crise da estrutura existente desde o final da II Guerra Mundial, mais do que propriamente o surgimento de uma nova ordem. Segundo o ministro das relações exteriores do Brasil durante o governo Lula da Silva, Celso Amorim (2010, p. 1), "a maior capacidade de articulação Sul-Sul - na OMC, no FMI, na ONU e em novas coalizões, como o BRIC - eleva a voz de países antes relegados a uma posição secundária". Ao mesmo tempo, a ascensão de novos interesses e demandas, bem como a rapidez das transformações, torna mais complexo o entendimento atual sobre a governança global. Nesse contexto de incertezas e mudanças, o Brasil parece adquirir uma nova posição de razoável proeminência, ancorada na melhoria da realidade econômica e social do país e em ativismo internacional que busca o fortalecimento da multipolaridade. Desde 1994 a inflação está nos padrões internacionais e o crescimento tem sido importante nos dez primeiros anos do século XXI, situando-se em 2010 em aproximadamente $8,5 \%$.

Mudanças ocorridas no sistema internacional, que não se apresentavam como cenários previsíveis antes dos anos noventa, influenciaram a política externa brasileira na primeira década do século XXI especialmente no governo Lula da Silva. Cabe destacar: 1) o processo de intensificação do unilateralismo norte-americano, especialmente durante os governos de W. Bush (2001-2008); 2) o impacto da ascensão da China; 3) a valorização das commodities agrícolas a partir de 2003; 4) a reestruturação dos eixos de desenvolvimento mundial, em particular o papel de Índia, Rússia e África do Sul; 5) o crescimento dos fluxos de comércio para países que até 1990 não eram relevantes para o Brasil; 6) o papel atribuído pelo Brasil às negociações econômicas multilaterais, evidenciado pela participação ativa do país no G-20 financeiro (VIGEVANI e RAMANZINI JÚNIOR, 2009). Esses elementos tiveram vigoroso impacto para o fortalecimento do universalismo enquanto matriz conceitual fundamental 


\title{
DOSSIÊ OS ANOS LULA
}

da inserção internacional. Além de projetar um lugar de destaque para o país nas discussões dos principais temas da agenda internacional, o ativismo externo brasileiro busca fortalecer o multipolarismo e as organizações internacionais como instâncias privilegiadas de ordenamento da estabilidade internacional.

A perspectiva brasileira, sobretudo no governo Lula da Silva, foi a de pesar no sistema internacional para estimular o multilateralismo, de forma não antagônica aos Estados Unidos, mas considerando seu possível debilitamento. A evolução dos acontecimentos a partir de 11 de setembro de 2001, aos poucos foram consolidando no núcleo central do governo brasileiro, que apesar da enorme assimetria de poder, particularmente militar, a favor dos Estados Unidos, a tendência de longo prazo seria a de um desgaste produzido pelas conseqüências da situação de over extension. Patriota (2008), então embaixador do Brasil em Washington, entende que

\begin{abstract}
embora os Estados Unidos permaneçam a única superpotência do sistema internacional, já não se pode dizer, hoje, que a ordem mundial se enquadre em um modelo rigorosamente 'unipolar'. Os recursos políticos e militares de que dispõem o governo e a sociedade norte-americanos, ainda que virtualmente incontrastáveis, não thes asseguram a capacidade de definir resultados em escala global (PATRIOTA, 2008, p. 98 , grifos do autor).
\end{abstract}

As dificuldades dos Estados Unidos, o fortalecimento da economia da China e da Ásia em geral, aumentaram a crença entre parte dos formuladores de política de que o multilateralismo se fortaleceria antes mesmo do aprofundamento das dificuldades no Iraque e no Afeganistão e da crise financeira de 2008. Por um lado, como evidenciado pela crise financeira, há uma diminuição na capacidade econômica dos Estados Unidos, por outro, há um fortalecimento do significado de outras regiões e países. Prevalece na sociedade brasileira, nos partidos políticos, seja os de governo seja os de oposição, a idéia que no mundo contemporâneo as formas de atuação e de resolução de problemas e conflitos, depende mais da negociação, de confidence building. Temas 
como pobreza, muito enfatizado pelo presidente Lula da Silva, terrorismo, migrações, ilícitos transnacionais, conflitos internos aos Estados, tensões bilaterais, devem ser enfrentados nessa perspectiva.

O objetivo brasileiro no governo Lula da Silva de contribuir para uma nova geometria de poder mundial não implica confronto com os países ricos, em particular com os Estados Unidos, nem com a União Européia. A Parceria Estratégica com a União Européia e o Diálogo de Parceria Global com os Estados Unidos sinalizam a importância atribuída aos países mais ricos. A diplomacia brasileira tem estratégias diferenciadas para diferentes áreas temáticas: segurança, comércio, direitos humanos, etc (VIGEVANI, 2010). No caso da MINUSTAH (Missão das Nações Unidas para a Estabilização do Haiti), evidenciou-se identidade com as posições norte-americana, francesa e canadense. $\mathrm{Na}$ questão do aumento do share das quotas no FMI e no Banco Mundial, que encontra resistência em países europeus, os Estados Unidos também foram simpáticos a posições como as do Brasil e da China. A aproximação entre Brasil e Estados Unidos no tema dos biocombustíveis, comprovada pela visita do presidente Bush ao Brasil em 2007, a aproximação de pontos de vista na reunião ministerial da OMC em julho de 2008, sinalizam posturas cooperativas. Em outras questões as diferenças vieram à tona, como no debate sobre as mudanças no Conselho de Segurança da ONU, onde o Brasil desejaria posição favorável de parte dos Estados Unidos. Também em temas latinoamericanos há divergências. Foi assim na crise de Honduras de 2009 e também na avaliação de alguns governos críticos dos Estados Unidos, como é o caso da Venezuela. Na questão do meio ambiente também há bastante distância entre as posições do Brasil e dos Estados Unidos e União Européia.

Repercutiu internacionalmente a atuação do Brasil e da Turquia no caso da busca de mediação frente ao impasse criado pela decisão iraniana de enriquecer urânio. Segundo o assessor especial da Presidência da República, Marco Aurélio Garcia (2010, p. 4 ), "o episódio do Irã foi a entrada na cena internacional de dois personagens que não tinham sido convidados, que entraram com uma proposta importante". 
A Declaração de Teerã de maio de 2010, articulada pelo Brasil e pela Turquia, incorporando exigências da Agência Internacional de Energia Atômica (AIEA), não evitou que o Conselho de Segurança da ONU, com o voto de Estados Unidos, Rússia e China, aprovasse sanções contra o Irã, ainda que limitada e fracas. Um aspecto significativo a ser destacado é que o apoio de Russia e China às posições norteamericanas demonstra que os países emergentes não são um grupo monolítico. Possívelmente, a ação turca e brasileira tenha contribuido parcialmente para a atenuação da resolução. A motivação do Brasil no caso do Irã e em outras ações em cenários não tradicionais, como havia sido em 1999 o envio de contingente militar a Timor Leste, de acordo com os governos brasileiros não significaria acreditar em influência acima de sua própria capacidade, mas traduziria uma diretriz que visa definir espaço nos problemas internacionais. Isto contribuiria para redesenhar regimes e relações.

\section{Busca de fortalecimento do multilateralismo}

A dinâmica do sistema internacional e a evolução dos anos 1990 e dos primeiros anos do século XXI afetam a todos os Estados. Mas a reação frente às transformaçõs globais apresenta especificidades. A intensificação do unilateralismo norte-americano na administração W. Bush (2001-2008) fortaleceu nos governos Cardoso (1994-2002) e Lula da Silva (2003-2010), particularmente neste último, o interesse por políticas ativas de articulação internacional voltadas aos grandes países emergentes e ao fortalecimento da multipolaridade. O país aumentou e institucionalizou parcerias com países e regiões não-centrais, como África, Oriente Médio, mas especialmente com a Ásia e a América Latina. A lógica da autonomia pela diversificação (VIGEVANI e CEPALUNI, 2007) que estrutura a política externa do governo Lula da Silva, baseia-se em uma tentativa de influenciar a agenda de regimes internacionais por meio de coalizões de países em desenvolvimento buscando aumentar o poder de barganha nas negociações com os países desenvolvidos. 
A presença ativa do Brasil na criação do G-20 comercial na fase final de preparação da Reunião Ministerial de Cancun da OMC, de setembro de 2003, resulta de uma decisão do governo que visava diminuir a capacidade impositiva dos países centrais. A posição brasileira evitou que os países desenvolvidos, especialmente os Estados Unidos e a União Européia, direcionassem os acordos da Rodada Doha dentro de uma lógica de pactuação assimétrica, tal como ocorreu nas rodadas anteriores de negociação do sistema GATT/OMC (Acordo Geral de Tarifas e Comércio/Organização Mundial do Comércio) (STEINBERG, 2002). Com a formação do G-20, a estratégia brasileira buscou contrastar os interesses comerciais dos países ricos e atingir maior equilíbrio nas negociações. Equilibrou a atenção aos interesses dos países em desenvolvimento com forte agribusiness, como Brasil e Argentina, aos com agricultura familiar de subsistência, como Índia, China.

A articulação do G-20 comercial e o papel de destaque no grupo colocaram o Brasil, juntamente com a Índia, no núcleo decisório da OMC. O ministro Amorim afirmou: "Diria sem falsa modéstia que o Brasil mudou a dinâmica das negociações da OMC. Não foi o Brasil sozinho. Mas o Brasil lidera o G-20 e é procurado - e diria que quase cortejado por Estados Unidos, União Européia e Japão, entre outros países" (BRASIL, 2006, p. 6). O prolongamento da Rodada Doha, o gerenciamento do G-20, ao menos até a reunião ministerial de julho de 2008, e o questionamento das políticas agrícolas dos Estados Unidos e da Uniao Européia no órgão de solução de controvérsias colocaram o Brasil como ator central do principal regime de comércio internacional o que possivelmente contribuiu para aumentar o peso do país em outros fóruns.

A reestruturação do poder mundial (KUPCHAN, 2002) nos anos 2000, tendo como fator dinâmico países tradicionalmente não centrais, como o demonstra o papel de Índia, Rússia, África do Sul, sobretudo da China, bem como as relativas mudanças na distribuição do comércio exterior brasileiro, foram acontecimentos que contribuíram para dar sustentação à busca de um papel internacional mais assertivo durante o 
governo Lula da Silva. Em 1989 o share de comércio do Brasil com os Estados Unidos foi $22 \%$, reduzindo-se a $12 \%$ em 2009. Com a União Européia no mesmo período a variação foi de $28 \%$ a $22 \%$. Inversamente, para a Ásia, por conta do peso da China, os dados evoluiram de $13 \%$ para $26 \%$ (SECEX, 2010).

Mesmo sem haver relação imediata entre os níveis econômico e político, essa dinâmica traduziu-se em intensa participação nas organizações internacionais, nas Missões de Paz, como exemplifica a participação do país na MINUSTAH, na busca pelo assento permanente no Conselho de Segurança da ONU, na articulação de coalizões multilaterais como o G-20 comercial na Rodada Doha da OMC, no grupo IBSA (India, Brazil e South Africa) e no grupo BRICs (Brazil, Russia, India e China). A crise financeira e econômica internacional desencadeada a partir do segundo semestre de 2008 não alterou a tendência de busca do fortalecimento do papel do país no mundo.

O comportamento brasileiro frente à crise financeira e econômica de 2008 demonstra que a ênfase na busca de um sistema mundial multipolar e do fim do unilateralismo se apoia na percepção de que a maximização de capacidades do país ocorre pela participação em diversos foros, políticos e econômicos, regionais e multilaterais. O presidente Luís Inácio Lula da Silva, ao fim da Cúpula do G-20 financeiro sobre Economia Mundial e Mercados Financeiros, realizada em Washington em novembro de 2008, concluía: "o dado concreto é que, pela força política, pela representação dos países que foram inseridos no G-20, eu penso que não tem mais nenhuma lógica tomar decisões sobre economia, sobre política, sem levar em conta esse fórum de hoje" (BRASIL, 2008, p. 4). A parcial substituição do G-8 pelo G-20 como foro privilegiado de interlocução dos líderes mundiais simboliza uma mudança significativa da configuração dos arranjos - mesmo que informais - da governança internacional. Podemos dizer que o Brasil busca o fortalecimento do papel dos grandes países emergentes, na perspectiva de um reconhecimento institucional formal, com benefícios gerais, mas fortalecendo a sua própria posição, portanto busca um jogo de soma positiva, com vantagens relativas em seu próprio favor. Isso 
explica a reiteração do esforço pela mudança da estrutura do Conselho de Segurança da ONU, pela alteração da distribuição das cotas de capital no FMI e no Banco Mundial, assim como o crescimento do perfil da intervenção política.

\section{Aspectos da política regional}

A evolução do quadro internacional discutida na seção anterior e as atitudes que prevaleceram no governo Lula da Silva frente a elas tem forte valor explicativo para o entendimento da política de integração regional. As elites e o governo buscaram maximizar o que acreditavam serem novas oportunidades, convencidas da necessidade de agilidade de decisões. O fortalecimento de relações globais, com o conjunto das regiões África, Oriente Médio, é um objetivo nacional, não necessariamente conjugado com a lógica regional. Os problemas colocados para a integração não são apenas relativos à economia e à política externa, mas referem-se à dificuldade de internalização da lógica da integração, mesmo continuando intensa a perspectiva da cooperação. O Brasil mostrou interesse no desenvolvimento econômico dos países da América do Sul, estimulando sua estabilidade política democrática e, na medida de sua relativamente pequena capacidade, contribuindo economicamente para alguns projetos importantes. Essa política indica uma perspectiva cooperativa na relação com os países da região.

O crescimento da economia mundial, a partir de 2001 até 2008, com destaque para o papel da China levou setores empresariais e grupos importantes no governo a reorientar o foco de seus interesses. Ainda que mantida a ênfase política na integração, ela teve seu significado proporcionalmente reduzido. O aumento do preço das commodities, inclusive do petróleo e do gás, bem como a liquidez observada no sistema financeiro, durante boa parte do governo Lula da Silva, colaboraram para o aumento das exportações, não só do Brasil, mas também dos outros países da região. Ainda que não tenha contribuído para o esforço de complementaridade produtiva e comercial regional, o bom momento internacional, parcialmente interrompido com 
a crise do segundo semestre de 2008 , foi importante para que os países mantivessem suas economias razoavelmente estáveis, ainda que com condicionalidades determinadas pela forte dependência de matériasprimas ou semielaborados na pauta das exportações. No caso das relações com a China, mesmo com os riscos da assimetria de intercâmbio em termos de valor agregado, as oportunidades oferecidas para grupos empresariais ou sociais consolidam uma dinâmica não diretamente convergente com a integração regional, pois seus benefícios independem da complementaridade produtiva regional.

Em virtude de sua base social original, o governo Lula da Silva poderia representar uma maior abertura para a integração. Parte dos partidos que the dão sustentação, em particular o Partido dos Trabalhadores, tradicionalmente são favoráveis à integração. O que observamos é que as políticas sociais e distributivas do governo são fatores que não necessariamente coincidem com as necessidades estruturais da integração regional. Posições nacionaldesenvolvimentistas podem ter um reflexo ambíguo para a integração regional, na medida em que enfatizam o grau de liberdade e de autonomia nacional na formulação de políticas e buscam tornar o país um ator protagonista no sistema internacional. Isso pode dar-se tanto na perspectiva de afirmação da autonomia como na perspectiva de que a integração é um fator de fortalecimento da capacidade de barganha internacional.

O governo Lula da Silva representou parcial mudança no equilíbrio das elites que sustentam o governo e o Estado, representou o mesmo no tocante ao pessoal dirigente. Nesse sentido, havendo maior autonomia relativa em relação a setores empresariais, poderse-ia admitir maior valor à lógica político-ideológica, ao simbolismo da integração regional. Mesmo sem ter sido desprezada esta lógica, até mesmo valorizada em algumas situações, as dificuldades estruturais parecem ter prevalecido. Colocam desafios para a integração, de difícil superação, os interesses de parte dos empresários brasileiros motivados pela busca de grandes mercados, a necessidade de relações com os países ricos e com os grandes países em desenvolvimento, a 
não complementaridade entre as economias e os interesses de grande parte da população, que não tem recursos básicos.

A Argentina foi o primeiro país que Lula da Silva visitou depois de eleito. A idéia de fortalecimento do Mercosul e da aliança estratégica sempre esteve presente. Na primeira reunião de Lula da Silva com o então presidente da Argentina, Eduardo Duhalde, em novembro de 2002, mencionou-se a necessidade de se retomar o PICE (Programa de Integração Comercial e Econômica) assinado pelos presidentes Sarney e Alfonsín em 1986. Por diversas vezes, afirmou-se a importância de uma política industrial e de financiamento comum. Com a eleição de Néstor Kirchner, em 2003, embora com uma política e um discurso favoráveis ao Mercosul e demonstrando compatibilidade ideológica com Lula da Silva, as medidas efetivamente tomadas por eles foram escassas. Observam-se posições comuns, em casos específicos, como na Cúpula de chefes de Estado das Américas, em Mar del Plata, em 2005, quando houve coincidência na ação visando o adiamento sine die das negociações da ALCA. De modo geral, no entanto, não houve esforços mais amplos de coordenação e convergência. Dessa forma, parece terse diluído o impulso inicial pelo desenvolvimento comum, embora subsista a busca de possíveis vantagens econômicas proporcionadas pelo aprofundamento do intercâmbio e pela atuação internacional conjunta em situações específicas. Houve alguns esforços dos presidentes Néstor e Cristina Kirchner e de Lula da Silva no sentido de favorecer investimentos de empresas estatais ou com financiamento do Banco Interamericano de Desenvolvimento (BID) e do Banco Nacional de Desenvolvimento Econômico e Social (BNDES) que privilegiassem as cadeias produtivas. Um passo concreto importante foi a efetivação do acordo para a criação do Sistema de Pagamentos em Moeda Local (SML), vigente a partir de outubro de 2008.

A partir de 2003, o Brasil passa a reconhecer de forma explícita a existência de assimetrias estruturais no Mercosul. As tentativas de oferecer contrapartidas aos outros sócios não tiveram a densidade necessária. Foi somente em 2006, quinze anos depois do Tratado de Assunção, que se implementou o Fundo de Convergência Estrutural, 


\section{DOSSIÊ OS ANOS LULA}

com recursos de US $\$ 100$ milhões, aumentados para US\$225 milhões no final de 2008, e que visavam atenuar as conseqüências desfavoráveis da integração nos Estados menores do bloco - Paraguai e Uruguai. A efetivação do Parlamento do Mercosul (Parlasul), em dezembro de 2006, foi um acontecimento com potencialidades importantes, sobretudo, no que se refere à possibilidade de maior internalização da lógica da integração e de socialização das elites políticas regionais. Ao mesmo tempo, a consolidação do Parlamento tem a ver com poderes reais, não apenas consultivos. É possível que o Parlamento do Mercosul torne-se uma nova nomenclatura de continuidade da Comissão Parlamentar Conjunta, mesmo com diferenças potencialmente virtuosas. Um teste será a complementação do processo para a eleição direta, cujo cronograma não está sendo cumprido conforme o estabelecido pelo Protocolo Constitutivo de 2005.

No governo Lula da Silva existe preocupação quanto aos limites colocados pelo formato da integração do Mercosul, mas ela não parece ser suficiente para superar as debilidades estruturais.

O Mercosul tem diante de si o desafio de reinventar-se
e atender às expectativas de todos os seus membros.
Temos de desenhar mecanismos que equacionem em
definitivo as assimetrias, inclusive com o aporte de
novos recursos. Precisamos encarar de frente as
questões relativas ao fortalecimento institucional e à
implementação, em cada um de nossos países, das
decisões acordos que tomamos no bloco. Esta nova
etapa do Mercosul que estamos iniciando exigirá que
suas instituições estejam à altura de nossas ambições
[...] Mais Mercosul significa, necessariamente, mais
institucionalidade (LULA DA SILVA, 2006).

Na sociedade brasileira, essa perspectiva não apenas não é consensual, como também enfrenta resistências, o que explica os parâmetros reais da ação do Estado.

Como notou Soares de Lima (2006), é importante considerar que a chegada ao poder de governos de esquerda na América do Sul não gerou necessariamente alinhamentos automáticos, pois esses governos tendem a ser mais sensíveis ao atendimento das demandas de suas 
respectivas sociedades, independentemente do efeito que suas ações possam ter para os processos de integração regional. Um exemplo emblemático nesse sentido foi o da nacionalização dos hidrocarbonetos, na Bolívia, promovida por Evo Morales em maio de 2006, e que afetou interesses da Petrobrás na Bolívia. Este episódio constitui-se em caso exemplar, pois permite avaliar as possibilidades e os limites de uma cooperação que tenha como pressupostos concepções de mundo e valores com alguma semelhança: crítica das desigualdades sociais, distância dos centros de poder mundial e idéias genericamente socialistas. No caso da Bolívia, tal como nos anos quarenta e cinqüenta ocorreu com o estanho, o gás é agora visto simbolicamente como valor a ser preservado para garantir a emancipação das populações pobres e historicamente marginalizadas. O mesmo ocorre no Paraguai onde, segundo Canese (2008, p. 25), a política do Estado visa a "recuperação da soberania hidrelétrica nacional". Como foi apontado, a percepção brasileira de que as afinidades abrem alguns caminhos e promovem a compreensão entre parceiros comerciais não deve impedir que se reconheça o fato de que a política regional e exterior relaciona-se sobretudo com aquilo que considera como seus interesses. Não basta vontade política, é necessário um desencadeamento de interesses que confluam na integração; caso contrário, prevalece a busca de soluções não cooperativas.

A expectativa gerada inicialmente pela emergência de forças políticas inovadoras e com bandeiras integracionistas fez vislumbrar a possibilidade de uma nova fase nas tentativas de avanço da integração no Mercosul e na América do Sul. As dificuldades próprias da integração na região, somadas aos diferentes níveis de compreensão de quais os caminhos para o desenvolvimento, causam problemas de difícil solução para os processos de integração da região. O governo brasileiro, desde 1993, com grande ênfase no governo Lula da Silva, vem consolidando o conceito de América do Sul, antes não existente ou secundário na formulação de estratégias regionais. O argumento dos diplomatas e dos dirigentes do Estado era de que o Mercosul seria o ponto de partida para a integração sul-americana. Isso corresponde a várias concepções, uma 
das quais é a de buscar alternativas frente às dificuldades da própria integração no Cone Sul. Outra se refere ao interesse brasileiro em poder agir no sistema internacional como um primus inter pares da região.

A estratégia universalista brasileira, de global player, reduz em termos relativos o papel do Mercosul e da América do Sul para o Brasil, mas pode aumentar o interesse no Brasil por parte dos vizinhos. A razão para isso ter acontecido durante o governo Lula da Silva, com boa possibilidade de continuidade é o crescimento econômico do país, que faz com que se torne um mercado crescentemente importante sobretudo para os países do Mercosul. Em valores absolutos, o comércio e os investimentos brasileiros na região aumentaram fortemente, fazendo crescer o interesse pelo Brasil, particularmente na Argentina e também no Chile. Esse é um movimento que tem impactos positivos para a integração.

\section{Considerações Finais}

A política externa brasileira tem alguns pilares. Fundamentais são os conceitos formadores do padrão de comportamento brasileiro, universalismo e autonomia, com a consequente busca de enfraquecimento do unilateralismo. Para isso a primeira década do século XXI ofereceu novas possibilidades, determinadas pelo crescente peso de alguns países. Alguns deles constituem pólos relevantes que contribuem para dar base concreta à política externa. Ao contrário dos países desenvolvidos, cujos recursos de poder econômico e militar garantem-Ihes influência internacional, ainda que com riscos de over extension, a projeção externa do Brasil é perseguida mediante intensa participação nos foros políticos e econômicos, regionais e multilaterais. Essa participação justifica-se pela busca de preservação do país frente aos riscos de vulnerabilidade e pela tentativa de aumentar o próprio poder.

A indefinição e as irregularidades no sistema internacional sugerem uma estratégia de inserção flexível às mudanças. Essa noção esteve presente nas formulações brasileiras em relação ao Mercosul, principalmente na defesa do intergovernamentalismo como princípio 
institucional da integração, evitando-se o supranacionalismo. Perspectiva mantida constante de 1991 até hoje, recentemente tem sido revalorizada, pois, no entendimento de parte das elites e do governo brasileiro, ela viabiliza a busca pelo multilateralismo - seu interesse maior. A criação do FOCEM (Fundo de Convergência Estrutural do Mercosul), do PARLASUL, também de outras instituições e organismos regionais durante o governo Lula da Silva, como a própria UNASUL, não alteraram o objetivo brasileiro de buscar garantir essencialmente uma coesão mínima no Cone Sul (MARIANO, 2007), compatível com os objetivos de projeção nacional universalista. A evolução do FOCEM e do Parlasul podem ser pensados como indicadores das próprias dificuldades da integração. A melhoria da classificação do Brasil pela agência de classificação de risco Moody's em setembro de 2009, fortalece o interesse do governo pelas relações globais. Esse interesse não esteve em contradição com a continuidade das atenções em relação ao Mercosul. Como estamos argumentando, o que se verifica durante o governo Lula da Silva é uma diminuição do peso relativo do bloco regional para a política externa e econômica do Brasil. Isso pode ser observado pelas dificuldades de coordenação de políticas nas negociações da OMC, inclusive na importante reunião de Genebra de julho de 2008. Referindo-se a esse fato, o presidente Lula da Silva afirma que "não houve divergência de conceitos" (LULA, 2008, p. 2). Mas reconhece que muitas vezes, em momentos críticos, prevalece nas decisões do governo a lógica nacional:

\footnotetext{
Veja, por mais que você trabalhe para um processo de integração, seja da União Européia ou da América do Sul ou do mundo asiático, em alguns momentos você tem que considerar a situação do seu Estado nacional. Não devemos ver, em nossas diferenças, situações de conflito mas situações de diferença; diferenças econômicas e de potencial industrial (LULA, 2008, p. 2).
}

É a avaliação de que o sistema internacional tende à multipolaridade que confere sentido à estratégia internacional do país. Mesmo com diferenças em aspectos específicos e pontuais, um largo espectro de atores sociais, políticos, economicos, Ihe dá sustentação 
doméstica. O multilateralismo surge normativamente como o cenário mais adequado e mais favorável para a discussão das questões globais. $\mathrm{Na}$ percepção brasileira as instituições e procedimentos multilaterais devem ser fortalecidos para lidar com os desafios em todos os campos, economico, político e de segurança. Da mesma forma, o objetivo de projetar o país como um ator relevante na política internacional foi um aspecto definidor da política externa do governo Lula da Silva.

Haroldo Ramanzini Júnior é doutorando em Ciência Política na Universidade de São Paulo (USP), Pesquisador do Centro de Estudos de Cultura Contemporânea (CEDEC) e do Instituto Nacional de Ciência e Tecnologia para Estudos sobre os Estados Unidos (INEU).

E-mail: hramanzinijunior@usp.br haroldo@cedec.org.br

\section{Referências:}

AMORIM, Celso L. N. Seven years of progress, expansion. The Miami Herald. 13 sep. 2010.2 Disponível em: <http://www.miamiherald.com/2010/09/12/1819845/seven-years-ofprogress-expansion.html>. Acesso em: 10 nov. 2010.

BRASIL não perdeu prestígio. Ele nunca foi tão alto. Gazeta Mercantil, Rio de Janeiro, 19 out. 2006, Entrevista, p. 6-8.

BRASIL volta da reunião com trunfos nas mãos. Gazeta Mercantil, Rio de Janeiro, 17 nov. 2008, Economia, p. 4.

CANESE, Ricardo. A recuperação da soberania hidrelétrica do Paraguai. In: CODAS, Gustavo (Org.). O direito do Paraguai à soberania. São Paulo: Editora Expressão Popular, 2008. p. 30-47.

EPSTEYN, Juan Cláudio. Evolución histórica de modelos institucionales de política comercial. Los casos de Estados Unidos e Brasil. 2009. 256 f. Tese (Doutorado em Ciência Política e Sociologia) - Instituto Universitário de Pesquisas do Rio de Janeiro, IUPERJ, [2009].

FARIA, Carlos Aurélio P. de. Opinião pública e política externa: insulamento, politização e reforma na produção da política exterior do Brasil. Revista Brasileira de Política Internacional, Brasília, v. 51, n. 2, p. 80-97, ago. 2008. 
FARIAS, Rogério de Souza; RAMANZINI JÚNIOR, Haroldo. Contra a corrente: democratização e política externa no Brasil. In: Encontro da ABCP, 7., 2010. Recife. Banco de Papers. Disponível em: <http://www.abcp2010.sinteseeventos.com.br/>. Acesso em: 12 out. 2010.

GARCIA, Marco Aurélio. Entrevista. O Estado de São Paulo, São Paulo, 09 ago. 2010. Caderno especial: Desafios do novo presidente, p. 4.

KUPCHAN, Charles A. Hollow hegemony or stable multipolarity? In: IKENBERRY, G. John (Org.). American Unrivaled: the future of the balance of power. Ithaca/London: Cornell University Press, 2002. p. 6898.

LAFER, Celso. A identidade internacional do Brasil e a política externa brasileira: passado, presente e futuro. São Paulo: Perspectiva, 2004.

LULA, en exclusiva con Clarín: 'no existe ninguna hipótesis de que Brasil se juegue solo'. Clarín, Buenos Aires, 07 sep. 2008. Disponível em: <http://edant.clarin.com/diario/2008/09/07/um/m-01755400.htm>. Acecsso em: 12 out. 2010.

LULA DA SILVA, Luiz Inácio. Discurso do presidente da República, Luiz Inácio Lula da Silva, por ocasião do encerramento da XXX Cúpula dos Chefes de Estado do Mercosul. Córdoba, julho de 2006. Disponível em: <http://www.mercosul.gov.br/discurso>. Acesso em: 02 dez. 2006.

MARIANO, Marcelo P. A Política Externa Brasileira, o Itamaraty e o Mercosul. 2007. 218 f. Tese (Doutorado em Sociologia) - Faculdade de Ciências e Letras, UNESP, [2007].

MURPHY, Craig N. International Organization and Industrial Change: Global governance since 1850. Cambridge: Polity Press,1994.

PATRIOTA, Antonio de Aguiar. O Brasil e a política externa dos EUA. Revista Política Externa, São Paulo, v. 17, n. 1, p. 97-109, jun.-ago. 2008.

PINHEIRO, Letícia. Política Externa Brasileira (1889-2002). Rio de Janeiro: Jorge Zahar, 2004.

SECEX. Ministério do Desenvolvimento, Indústria e Comércio-Brasil, 2010. Dados Estatatisticos. Disponível em: <http://www.desenvolvimento.gov.br/sitio/interna/interna.php?area $=5$ \&menu=2033\&refr=576>. Acesso em: 06 out. 2010.

SOARES DE LIMA, Maria Regina. Decisões e indecisões: Um balanço da política externa no primeiro governo do presidente Lula. Carta Capital, 27/12/2006. Disponível em: <http://observatorio.iuperj.br>. Acesso em: 12 set. 2010. 
Brasil e pólos emergentes do poder mundial: Rússia, Índia, China e África do Sul. In: BAUMANN, Renato (Org.). O Brasil e dos demais BRICs - Comércio e Política. Brasília, CEPAL/IPEA, 2010. p. 155185.

STEINBERG, Richard. In the shadow of law or power? Consensus based bargaining and outcomes in the GATT/WTO. International Organization, Massachusetts, v. 56, n. 2, p. 339-374, spring 2002.

VIGEVANI, Tullo. Relações Brasil-Estados Unidos. Mimeo. 2010.

VIGEVANI, Tullo; CEPALUNI, Gabriel. A Política Externa de Lula da Silva: A Estratégia da Autonomia pela Diversificação. Contexto Internacional, Rio de Janeiro, v. 29, n. 2, p. 273-335, ago. 2007.

VIGEVANI, Tullo; RAMANZINI JÚNIOR, Haroldo. Mudanças da inserção brasileira na América Latina. Lua nova, São Paulo, n. 78, p. 37-75, out. 2009.

Texto recebido em 30/09/2010.

Aprovado em 16/11/2010. 